\title{
Regionalização da Sober: a experiência do Nordeste ${ }^{1}$
}

\author{
Tales Vital ${ }^{2}$, Yony Sampaio ${ }^{3}$, Amilcar Baiardi ${ }^{4}$, \\ João Ricardo Lima ${ }^{5}$ e André Melo ${ }^{6}$
}

Resumo: Este artigo analisa a estratégia de descentralização adotada a partir de 2005 pela Coordenação Regional Nordeste da Sociedade Brasileira de Economia Administração e Sociologia Rural (Sober) através da realização de encontros anuais da sociedade em cidades de porte médio de estados do Nordeste. Essa iniciativa teve como propósito a interiorização dessa sociedade científica, cujos efeitos são analisados à luz do método histórico aplicado à gerência de organizações, como caminho para verificar os impactos sobre a organização desse procedimento adotado. Os resultados obtidos indicam efeitos positivos de crescimento da sociedade na região, podendo ser um caminho de melhoria das condições de sustentabilidade dessa organização no País.

Palavras-chaves: Sober Nordeste, descentralização administrativa, regionalização Sober.

\begin{abstract}
This article analyzes the decentralization strategy adopted since 2005 by the Northeast Regional Coordination of the Brazilian Society of Economics, Administration and Rural Sociology (Sober) through the organization of annual meetings in mediumsized cities in Northeastern states. The purpose of this initiative was the internalization of this scientific society, whose effects are analyzed based on the historical method applied to management organizations, as a way to verify the impacts on the organization of this adopted procedure. The results indicate growth effects of the society in the region, and it can be a mean of improving the sustainability conditions of this organization in Brazil.
\end{abstract}

Key-words: Sober Northeast, administrative decentralization, Sober regionalization.

Classificação JEL: N00, O39, R19, Z00.

DOI: http://dx.doi.org/10.1590/1234-56781806-94790560110

1. Data de submissão: 13 de fevereiro de 2017. Data de aceite: 17 de setembro de 2017.

2. Universidade Federal Rural de Pernambuco, Recife, Pernambuco, Brasil. E-mail: talesvital@hotmail.com

3. Universidade Federal de Pernambuco, Recife, Pernambuco, Brasil. E-mail: yonysampaio@gmail.com

4. Universidade Católica do Salvador, Salvador, Bahia, Brasil. E-mail: amilcar.baiardi@gmail.com

5. Empresa Brasileira de Pesquisa Agropecuária, Petolina, Pernambuco, Brasil. E-mail: joao.ricardo@embrapa.br

6. Universidade Federal Rural de Pernambuco, Recife, Pernambuco, Brasil. E-mail: andredesouzam@gmail.com 


\section{Introdução}

Este texto procura descrever os caminhos que foram percorridos nestes últimos anos pelos sócios da Sociedade Brasileira de Economia, Administração e Sociologia Rural (Sober) residentes no Nordeste para realizarem encontros regionais da Sociedade na região.

A estratégia de Regionalização da Sober tinha e ainda tem como propósito fortalecer a entidade na região e também no País e facilitar a realização dos congressos nacionais, preferencialmente nas capitais de estados das cinco regiões. A representação regional tem procurado, de alguma forma, assumir papel de apoio na realização desses eventos, muitas vezes no seu próprio estado. O núcleo de decisão dentro da Sober reflete a distribuição e peso relativo dos grupos de pesquisa instalados no País e vinculados à Sociedade, com maior participação para o Sudeste, Sul e Centro-Oeste, e menor no Nordeste e Norte. Nos congressos nacionais é natural que sócios dessas regiões, em maior número, ocupem mais espaço na condução desses eventos, haja vista uma maior tradição em pós-graduação e pesquisa voltada para o meio rural. Até pouco tempo, era designada aos membros da região Norte e Nordeste uma posição predominantemente de apoio, mesmo quando os eventos anuais eram realizados nessas regiões. De alguma forma, a participação secundária dessa parte da comunidade científica nos eventos nacionais levou grupos de pesquisadores do Nordeste a manifestações sobre a necessidade de se criarem maiores oportunidades de debates regionais, independentes da entidade. Outros grupos da região defenderam que esses debates se dessem no âmbito da própria sociedade científica, fortalecendo, assim, a entidade. Prevaleceu a segunda opção, e o passo seguinte foi colocar em marcha o projeto de encontros regionais inicialmente mal compreendidos pela direção da Sober, que via com preocupação a sustentabilidade financeira desses encontros e o consequente esvaziamento do congresso nacional em decorrência dessa iniciativa da coordenação regional Nordeste da Sober. Entretanto, essa visão foi, posteriormente, completamente superada devido à obtenção de financiamento na região e ajuste de calendário.

O problema de pesquisa deste artigo é saber, depois de 10 anos dessa experiência, se esse caminho de ação regional da Sober tem levado a entidade a um crescimento diferenciado no Nordeste, com a expansão do número de associados e também de participantes com trabalhos científicos apresentados nos congressos nacionais.

Além desta introdução, o artigo segue com os itens que tratam de aspectos teóricos e metodológicos, análise e interpretação dos resultados obtidos, conclusão, bibliografia e anexos.

\section{Aspectos teóricos e metodológicos}

Dentro do planejamento estratégico das organizações, os diferentes arranjos de suas ações no espaço em que atua são decisivos para o crescimento das mesmas. No caso Sober, até recentemente, a manutenção de apenas um Congresso Anual no território nacional 
não estava dando conta das transformações em curso nas regiões do País, que se acentuaram com a interiorização de universidades e institutos federais com atividades de pesquisa, ensino e extensão. A estratégia que vinha sendo utilizada dificultava o acesso de novos pesquisadores distribuídos pelo interior das regiões do país a esse evento, quer devido ao custo de participação vinculado ao congresso anual, quer por desinformação ou motivação para participar, colocando a Sober longe de sua clientela. A experiência de regionalização surgiu também dessa necessidade: aproximar a Sociedade de sua potencial clientela dentro de um país continental e com expansão de suas fronteiras agrícolas.

Essa regionalização é prática comum nos Estados Unidos, por exemplo, onde as associações nacionais têm capítulos regionais fortes, com promoção de encontros regionais.

Para verificar os efeitos dessa experiência adotada pela Sociedade, utilizou-se como método de trabalho o resgate histórico, que compreende: i) a heurística, operação sistemática de identificação das fontes e obtenção de informações necessárias à análise histórica ao longo do período analisado; ii) a crítica, na qual se avalia a validade ou não dessas fontes e das diversas versões contraditórias dos fatos; iii) a interpretação, que possibilita formar produtos narrativos que servem de fios condutores do trabalho a partir de informações retiradas das fontes; iv) a hermenêutica, entendida como resultado da interpretação de fatos e documentos obtidos, de modo a saber em que medida as informações fornecidas por esses elementos trazem respostas às questões inicialmente formuladas, ou seja, verificam-se os fatos que exteriorizam as intenções das ações pretendidas no passado; v) a analítica, em que esses processos têm o tempo como limite definidor do contexto e da possibilidade de agir; vi) e a dialética, que extrai das fontes tanto a intencionalidade da ação quanto o fator de mudança no tempo, inerentes à experiência em curso (SILVA, 2009). Este resgate está sempre relacionado ao emprego de investigação sistemática e racionalmente conduzida em busca de verdade dos fatos ao longo do tempo e a exposição na forma de relato e análise (BARROSO, 2014).

Qualquer introdução ao estudo da história apresenta como método os processos ou conjunto de operações de análise e a síntese. A análise decide sobre a autoridade da fonte de informação, sobre sua credibilidade e força de argumentação. A síntese conduz à produção histórica propriamente dita (CONSTANTINO, 2016). Ainda sobre esse método, a análise da organização no ambiente social em que nasceu permite uma melhor compreensão, no que diz respeito à sua gênese e posterior desenvolvimento, assim como às sucessivas alterações ocorridas (LOKATUS e MARCONI, 2003). Segundo Sauerbronn e Faria (2016), o método histórico vem sendo utilizado em pesquisas de gerência estratégica de organizações e em estudos de sociologia das organizações; portanto, pode ser considerado como adequado para essa pesquisa de regionalização da Sober, como estratégia de crescimento dessa Sociedade. Esses autores explicam o emprego da análise histórica em pesquisas organizacionais, cuja síntese pode ser assim referida: o histórico cultural da organização reflete no presente o seu comportamento e estrutura; o passado explica as tendências atuais na identificação de problemas organizacionais e o encaminhamento de suas soluções; as oportunidades podem ser mais bem identificadas e aproveitadas quando se tem a análise histórica da organização; ao se formular teorias sobre o desenvolvimento histórico organizacional essas têm mais aderência quando embasadas em dados de longo prazo.

Na utilização desse método é necessário que o pesquisador seja capaz de extrair dos fatos empíricos aquilo que é essencial para reconstituição de uma determinada realidade histórica (LESCURA et al., 2009). Esse caminho foi o adotado na construção deste trabalho.

No plano operacional, a pesquisa compreendeu o resgate e análise de: i) registros de filiados da Sober por estado do País nos últimos seis anos (20112015); ii) documentos dos congressos da Sociedade nesse mesmo período; iii) documentos dos últimos 10 encontros anuais da entidade em cidades do interior de estados do Nordeste (2005-2015) ${ }^{7}$, os quais refletiam a desconcentração das ações da entidade no País, junto a outras ações realizadas nas demais regiões, afora os encontros nacionais. $\mathrm{Na}$ análise desses dados procurou-se verificar se essa descentralização teve efeito positivo e diferenciado sobre a expansão localizada dos quadros de sócios da Sober, podendo, caso se confirme como positivo, a partir da discussão desses dados, ser uma das estratégias para o crescimento e fortaleci-

7. Em 2006 não houve o segundo encontro regional Nordeste da Sober porque ocorreu na região o Congresso Nacional da Sober, na cidade de Fortaleza, capital do Ceará. 
mento da organização e de grupos de pesquisa vinculados à entidade em todo o País.

Assim, esta pesquisa vem contribuir para o entendimento da realidade organizacional dessa Sociedade científica vinculada às questões rurais no País e suas implicações territoriais e internacionais.

\section{Análise e discussão dos resultados}

\subsection{Os encontros regionais}

Neste tópico procura-se registrar a dinâmica utilizada para realizar os encontros regionais da Sober, bem como fazer um relato dos resultados decorrentes desses encontros, na perspectiva de contribuir para o desenvolvimento científico e tecnológico da região.

\subsubsection{Estados, locais e participantes}

Os encontros foram realizados em seis estados da região de 2005 a 2015, conforme distribuição constante no Quadro 1. Registra-se a realização de três encontros em Pernambuco, dois na Bahia e apenas um encontro nos estados de Alagoas, Paraíba, Rio Grande do Norte, Ceará e Piauí. Falta incluir nesse circuito os estados de Sergipe e do Maranhão, onde ainda não houve encontro regional da Sociedade. A centralização dos encontros em dois estados tem refletido a participação mais ativa de seus grupos de pesquisa dentro da Sociedade.
A realização desses encontros em cidades de porte médio no interior dos estados da região decorre do fato de essas cidades fazerem parte da expansão do ensino superior no País. Todas essas cidades onde os encontros foram realizados têm campus avançados de universidades federais, ou estaduais, ou institutos federais, ou sedes de unidades de pesquisa da Embrapa, ou ainda, unidades de ensino superior privado, além de estrutura para evento das próprias prefeituras, tendo essas estruturas, mais de uma vez, servido de base para realizar as reuniões.

Nesses 10 encontros regionais foram mobilizadas 2.221 pessoas, distribuídas entre professores pesquisadores da rede universitária federal, estadual e privada do País e do exterior, estudantes universitários, pesquisadores da rede nacional de pesquisa agropecuária, técnicos de órgãos de planejamento nacional e estadual, técnicos de fomento à pesquisa e de instituições de desenvolvimento regional. Teve-se, em média, nesse período, um pouco mais de 200 pessoas por encontro. A Tabela 1 apresenta o número de participantes por ano. Os primeiros encontros de Petrolina (PE), Cruz das Almas (BA), Campina Grande (PB) e Mossoró (RN), foram os que tiveram menos participantes, de 100 a 200 pessoas.

Os encontros de Ilhéus (BA), Caruaru (PE), Crato (CE) e o segundo de Petrolina (PE) foram os que reuniram mais de 300 participantes, ou seja, grande presença de interessados. Na faixa intermediária ficaram Parnaíba (PI) e Arapiraca (AL), com mais de 200 e menos de 300 congressistas.

Quadro 1. Encontro Regional Nordeste da Sober: 2005-2015

\begin{tabular}{|c|c|c|c|l|}
\hline Encontro & Data do encontro & Estado & Município & \multicolumn{1}{|c|}{ Local do encontro } \\
\hline 1 & 28 e 29 (abr. 2005) & PE & Petrolina & Cento de Convenções da Prefeitura de Petrolina \\
\hline 2 & 21 a 23 (nov. 2007) & BA & Cruz das Almas & $\begin{array}{l}\text { Empresa Brasileira de Pesquisa Agropecuária (Embrapa) - } \\
\text { Mandioca e Fruticultura }\end{array}$ \\
\hline 3 & 22 a 25 (out. 2008) & RN & Mossoró & $\begin{array}{l}\text { Universidade Estadual do Rio Grande do Norte (Uern) - } \\
\text { Campus Central de Mossoró }\end{array}$ \\
\hline 4 & 3 a 5 (nov. 2009) & PB & Campina Grande & Embrapa - Algodão \\
\hline 5 & 24 a 26 (nov. 2010) & CE & Crato & Universidade Regional do Cariri (Urca) \\
\hline 6 & 19 a 21 (out. 2011) & PE & Petrolina & Faculdade de Ciências Aplicadas e Sociais de Petrolina (Facape) \\
\hline 7 & 6 a 8 (nov. 2013) & BA & Ilhéus & Universidade Estadual de Santa Cruz (Uesc) \\
\hline 8 & 6 a 8 (nov. 2013) & PI & Parnaíba & Universidade Federal do Piauí (UFPI) - Campus de Parnaíba \\
\hline 9 & 29 a 3 (out. 2014) & PE & Caruaru & $\begin{array}{l}\text { Universidade Federal de Pernambuco UFPE - Centro Acadêmico } \\
\text { do Agreste }\end{array}$ \\
\hline 10 & 18 a 20 (nov. 2015) & AL & Arapiraca & $\begin{array}{l}\text { Centro de Convenções Planetário de Arapiraca - da Prefeitura e } \\
\text { Universidade Federal de Alagoas (UFAL) - Campus de Arapiraca }\end{array}$ \\
\hline
\end{tabular}

Fonte: Material de divulgação dos encontros (SEJAM PROMOÇÕES E TREINAMENTO, 2005; UFRB/EMBRAPA, 2007; UERN, 2008; UEPB/EMBRAPA, 2009; URCA, 2010; FACAPE, 2011; UESC, 2012; UFPI-REDE PRODEMA, 2013; UFPE-CAA, 2014; UFAL-ARAPIRACA, 2015). 
Tabela 1. Participantes do Encontro Regional Nordeste da Sober: Pessoas e Instituições

\begin{tabular}{cccc}
\hline \multirow{2}{*}{ Ano } & Local do encontro & \multicolumn{2}{c}{ Participantes } \\
\cline { 3 - 4 } & & No Pessoas & No Instituições \\
\hline 2005 & Petrolina - PE & 172 & 39 \\
2007 & Cruz das Almas - BA & 108 & 17 \\
2008 & Mossoró - RN & 121 & 48 \\
2009 & Campina Grande - PB & 100 & 21 \\
2010 & Crato - CE & 360 & 60 \\
2011 & Petrolina - PE & 327 & 72 \\
2012 & Ilhéus - BA & 525 & 78 \\
2013 & Parnaíba - PI & 219 & 65 \\
2014 & Caruaru - PE & 385 & 56 \\
2015 & Arapiraca - AL & 240 & $*$ \\
\hline
\end{tabular}

* Informação não disponibilizada nos anais.

Fonte: Relatórios dos encontros regionais NE da Sober.

Em relação às instituições participantes desses encontros, destacam-se como financiadoras o Banco do Nordeste do Brasil (BNB), Banco do Brasil (BB), Conselho Nacional de Desenvolvimento Científico e Tecnológico (CNPq), órgãos estaduais de fomento à pesquisa, como a Fundação de Amparo à Ciência e Tecnologia de Pernambuco (Facepe), Fundação de Amparo à Pesquisa do Estado de Alagoas (Fapeal), Fundação de Apoio à Pesquisa do Rio Grande do Norte (Fapern), Fundação de Amparo à Pesquisa do Estado da Bahia (Fapesb), apenas para citar algumas, e a rede do Serviço Brasileiro de Apoio às Micro e Pequenas Empresas (Sebrae).

Além das entidades promotoras já citadas, Uern, Urca, Uesc, Facape, UFPI, Ufal (Quadro 1), são destaques a Universidade Federal do Recôncavo da Bahia (UFRB), Universidade Federal de Campina Grande (UFCG), Universidade Estadual da Paraíba (UEPB), e a rede Embrapa, com as unidades Semiárido e Meio-Norte e as unidades Mandioca e Fruticultura e Algodão, que sediaram dois desses encontros, as de apoio, como prefeituras municipais, empresas privadas em alguns estados, tais como gráficas, agências de automóvel, agências de viagem, entre outras.

Destaque também deve ser dado para as instituições dos participantes, que na maioria das vezes têm financiado as despesas de ida aos encontros de seus técnicos, professores e alunos. Entre as instituições que têm participado assiduamente com seus pesquisadores apresentando trabalhos, estão, além das promotoras dos encontros, outras universidades e faculdades da região e de outras regiões do País, como a Universidade
Federal Rural de Pernambuco (UFRPE), Universidade Estadual de Pernambuco (Uepe), Universidade Federal do Ceará (UFC), Universidade Estadual Vale do Acaraú (UVA), Universidade Estadual do Ceará (Uece), Universidade Federal do Rio Grande do Norte (UFRN), Universidade Federal da Paraíba (UFPB), Universidade Estadual de Feira de Santana (UEFS), Universidade Estadual do Sudeste da Bahia (Unesb), Universidade Federal Rural do Semiárido (Ufersa), Universidade Federal do Vale do São Francisco (Univasf), Universidade Federal da Bahia (UFBA), Universidade Católica do Salvador (Ucsal), Universidade Estadual de Alagoas (Ueal), Universidade Estadual do Piauí (Uespi), Universidade Federal do Maranhão (UFMA), Universidade Estadual do Maranhão (Uema), Universidade Federal de Sergipe (UFS), Universidade Federal de Viçosa (UFV), Universidade Federal do Rio Grande do Sul (UFRGS), Universidade de Brasília (UNB), Universidade Federal de Minas Gerais (UFMG) e Universidade Federal do Triângulo Mineiro (UFTM). A interiorização da Sober no Nordeste chega também ao interior de estados de outras regiões do país. Nesses encontros tem sido comum a apresentação de trabalhos de pessoas de diversos locais, tais como Universidade Federal de Uberaba (UFU), Universidade Federal do Pampa (Unipampa), Universidade Federal do Oeste do Pará (Ufopa), Universidade de Santa Cruz do Sul (Unisc), Universidade do Vale do Rio dos Sinos (Unisinos), entre outras.

O importante da regionalização é que os encontros do Nordeste têm atraído pesquisadores de universidades do Norte ao Sul do país e mesmo do 
exterior, com registros da Universidade do MinhoBraga/Portugal, Université Pierre Mendes, Granoble/ França, Universidade de Barcelona - Barcelona/ Espanha, University of Illinois at Urbana - Champaign /EUA, Universität Hohenheim, Stuttgart/Alemanha e Universidade Nacional de Asuncíon - Asuncion/ Uruguai.

\subsubsection{Dinâmica dos encontros e temas}

O primeiro encontro regional, como já referido, ocorreu em Petrolina (PE), em 2005, no Centro de Convenções da Prefeitura, com o tema: "1o Fórum Regional: Economia Agrícola". A iniciativa de realizar esse evento foi do Prof. Écio de Farias Costa, do Departamento de Economia da UFPE, que contou com a participação do Conselho Regional Nordeste da Sober, através de seus representantes, e também teve a autorização da diretoria da Sober para utilizar o nome da entidade. Esse evento constou de cinco mesas redondas e 16 palestras. Os assuntos tratados nas mesas versaram sobre desenvolvimento sustentável, irrigação na agricultura familiar, agricultura irrigada, tecnologia e mercado, sustentabilidade dos recursos hídricos, entre outros. Afora as mesas, houve também apresentação de 96 trabalhos na forma de pôster.

O segundo encontro foi marcado depois de uma avaliação positiva do primeiro pelo Conselho Regional da Sociedade. Como em 2006 o encontro nacional da Sober ocorreu em Fortaleza (CE), o segundo foi realizado em 2007, na cidade de Cruz das Almas (BA), sob a coordenação do prof. Amilcar Baiardi, à época vinculado à Escola de Agronomia da UFRB localizada nessa cidade. Foi ele quem compôs a equipe local, tendo a sustentação da Embrapa - Mandioca e Fruticultura, cuja sede também fica nesse município e que cedeu suas instalações para a realização do evento. O tema central foi "Pobreza Rural, Intervenções e Possibilidades de Desenvolvimento Sustentável". Esse encontro teve uma mesa redonda com o tema desenvolvimento sustentável e mudanças sociais, e foram também apresentados oralmente 71 trabalhos e mais 16 em pôster. Adotou-se nesse encontro procedimento semelhante ao do Congresso Nacional da Sober, incluindo na programação a assembleia ao final, quando foi decidido o próximo encontro, em Mossoró, proposta apresentada pela Profa. Genivalda Cordeiro da Costa do Departamento de Economia da Uern - campus Central Mossoró. A professora Genivalda levou a proposta para o seu Departamento, que tratou de montar a comissão local com membros da Ufersa e da UFRN para realizar o evento. O tema central escolhido foi "Fruticultura e Bioenergia: Estratégias de Desenvolvimento para o Nordeste" e contou com três mesas redondas e uma palestra, somadas à apresentação de 90 trabalhos técnico-científicos. Os temas das mesas foram sobre fruticultura, bioenergia e agroindústria na região. A palestra tratou do mercado internacional e do agronegócio brasileiro. Em Mossoró foi decidido que o próximo encontro seria em Campina Grande (PB), embora a responsabilidade local ainda não estivesse definida. Um pequeno grupo, junto ao Conselho Regional da Sober, ficou com a missão de ajudar a montar a equipe local. A proposta foi levada para o Prof. Robério Ferreira dos Santos, da UFCG, e o Prof. Cidoval Morais de Souza, da UEPB, e os dois assumiram a realização do quarto encontro regional da Sober em Campina Grande. O grupo local de gestão do evento foi formado com envolvimento de técnicos da Embrapa-Algodão, onde o evento foi realizado e teve como tema central "Conhecimento, Território e Sustentabilidade: Desafios para o Desenvolvimento Rural do Nordeste". A palestra de abertura versou sobre a contribuição da pesquisa e da tecnologia para o desenvolvimento rural da região. Nesse encontro houve cinco mesas redondas, tratando de assuntos como a situação da demanda de etanol no mundo e no País, o financiamento do desenvolvimento rural, o mercado da manga e os efeitos da crise econômica mundial sobre as frutas do Nordeste. Houve apresentação oral de 18 trabalhos e mais 20 na forma de pôster. Na solenidade de avaliação e encerramento, definiu-se o próximo encontro (quinto), a ser realizado no Ceará. A professora Francisca Laudeci Martins Souza, da Universidade Regional do Cariri (Urca), com sede no município do Crato, assumiu a organização do encontro na condição de coordenadora geral, e a Professora Eliane Pinheiro de Souza, também da Urca, posteriormente se responsabilizou pela coordenação científica do evento. O tema desse quinto encontro tratou das "Mudanças Climáticas Globais e Desenvolvimento Rural do Nordeste: Impactos Econômicos, Sociais e Ambientais", sendo também o tema da palestra de abertura. As três mesas redondas organizadas trataram de desertificação na região, financiamento do desenvolvimento em base sustentável e o andamento 
da pesquisa científica nesse meio rural. No encerramento foi abordada a gestão dos recursos de uso comum no semiárido do Nordeste. Foram apresentados oralmente 116 trabalhos e mais 14 pôsteres. Nesse encontro o Prof. João Ricardo, da Embrapa Semiárido e da Facape, assumiu a responsabilidade de organizar o sexto encontro, mais uma vez em Petrolina (PE), com o pessoal residente no município e com o apoio da equipe formada por membros dessas duas instituições e de outras. Teve como tema central "Nordeste: Desafios do Desenvolvimento para a Inclusão Social". A conferência de abertura tratou das desigualdades regionais no Brasil, enfocando suas causas e soluções, e a conferência de encerramento levantou a questão da distribuição de renda no país e na região. As três mesas redondas formadas cuidaram de questões como competitividade, políticas de desenvolvimento da região e necessidade e oportunidade de estudos localizados. Teve apresentação oral de 146 trabalhos e mais 45 na forma de pôster.

$\mathrm{Na}$ assembleia foi decidido realizar o sétimo encontro no município de Ilhéus, litoral Sul da Bahia, com o apoio da Profa. Naisy Silva Soares, da Uesc, que aceitou a missão e montou sua equipe. $\mathrm{O}$ tema central desse encontro foi "Políticas Públicas: Agricultura e Meio Ambiente". Na abertura, houve duas palestras: uma tratou da agricultura na América Latina e a outra, da agricultura na Ásia e na África, ambas na perspectiva do desenvolvimento. As duas mesas redondas do encontro versaram sobre governança ambiental e agrícola, considerando certificação, código florestal, os novos investimentos na região Nordeste e a sustentabilidade. Nessa mesma linha ocorreu um painel sobre novos caminhos para a agricultura da região, considerando pobreza, desigualdade e desenvolvimento com sustentabilidade. No encerramento houve mais duas conferências: uma sobre economia ecológica e outra sobre política ambiental. Foram apresentados oralmente 116 trabalhos e mais 12 na forma de pôster. Na assembleia foi decidido levar o oitavo encontro regional para um estado da região que ainda não tivesse sido contemplado, e a escolha foi o Piauí, mais especificamente o município de Parnaíba, dada a sua importância ambiental. O Prof. João Ricardo ficou encarregado de tratar da questão junto a professores do seu relacionamento na Universidade Federal do Piauí (UFPI) e também da equipe técnica da Embrapa Meio Norte. O Prof. José Natanael Fontenelle de Carvalho, da UFPI, assumiu a coordenação do encontro de Parnaíba (PI), que teve como tema central "Pluralidades Econômicas, Sociais e Ambientais: Interações para Reinventar o Nordeste Rural". A conferência de abertura tratou de estratégias de desenvolvimento para o Nordeste. Outra conferência versou sobre a contribuição de Celso Furtado para reinvenção do Nordeste rural. As duas mesas redondas estabelecidas foram centradas no desenvolvimento rural da região e nas políticas rurais do Piauí. Houve apresentação oral de 191 trabalhos. A proposta da Assembleia foi levar para Caruaru (PE)/Campus da UFPE o nono encontro regional da Sociedade, ficando o Prof. João Ricardo de verificar a exequibilidade da proposta, tendo, posteriormente, a Profa. Monaliza de Oliveira Ferreira, da UFPE-CAA, assumido esse compromisso e ficado como responsável. O tema central desse nono encontro foi "Novos Desafios para o Desenvolvimento: O Nordeste tem Sede de que?", tendo esse tema sido objeto da Aula Magna. As duas mesas redondas formadas trataram de desafios do desenvolvimento do semiárido da região e da questão do desenvolvimento rural-urbano. Houve apresentação oral de 156 trabalhos e de 18 na forma de pôster. $\mathrm{Na}$ assembleia ficou decidido levar para Alagoas o décimo encontro, tendo o Prof. João Ricardo ficado com a responsabilidade de viabilizar a proposta junto a parceiros da Universidade Federal de Alagoas, Campus de Arapiraca. A coordenação local ficou com o Prof. Renato Luís Pinto de Miranda, da Ufal-Arapiraca, que tratou de viabilizar o evento com o tema central "Desenvolvimento e Crise: e o Nordeste Como Fica?", refletindo a conjuntura do momento. Na conferência de abertura se tratou das mudanças do mundo rural do País. Durante o evento foram apresentadas cinco mesas redondas, abordando questões relativas a microcrédito, tecnologias para o semiárido, comportamento do setor sucroalcooleiro, que é importante em Alagoas, desenvolvimento à luz da economia ecológica e a experiência da regionalização da Sober. Foram também apresentados 135 trabalhos técnico-científicos. Nesse encontro as técnicas Andreya Raquel e Jéssica Samara, da Uern - Campus de Mossoró, pleitearam realizar em 2016 o $11^{\circ}$ encontro regional Nordeste da Sociedade, mais uma vez em Mossoró (RN). 


\subsubsection{Trabalhos apresentados por área temática}

Conforme tratado na Tabela 2, os trabalhos selecionados nos encontros regionais da Sober no Nordeste estiveram concentrados em número, nos temas Desenvolvimento no Meio Rural, com destaque para Sustentabilidade, o Agronegócio com os Sistemas Produtivos, Cadeias e Arranjos Produtivos, seguido pela Comercialização e Mercados de Produtos Agrícolas, pelas Análises de Políticas Públicas e Reforma Agrária. Esse bloco de temas concentrou $72 \%$ dos artigos apresentados nos encontros.

Outros temas menos frequentes versaram sobre Agricultura Familiar e Ruralidade, Territórios, Ruralidade e Desenvolvimento, seguidos pelos de Agricultura, Tecnologia, Inovação e Difusão, que somam $20 \%$ do total. Numa terceira e última posição menos significativa, com $8 \%$ do total, estão os trabalhos sobre temas como Economia Solidária, Emprego, Empreendedorismo e Gestão no Campo, Comércio Exterior Agrícola, Questões Rurais e Educação.

Essa diversidade de temas cobre amplo campo de interesse de pesquisadores que estiveram nos encontros regionais da Sober. A questão da agricultura e do meio ambiente tem estado cada vez mais presente na pauta de pesquisa.

\subsubsection{Minicursos realizados}

Uma grande contribuição desses encontros tem sido oferecer aos inscritos, treinamento em tópicos avançados. Durante o período analisado, em quatro desses encontros foram oferecidos 24 minicursos. No Crato (CE), nas instalações da Urca ocorreram quatro desses minicursos, versando sobre avaliação de políticas públicas, uso de econometria de séries temporais para análise de preços e ainda sobre sustentabilidade e desenvolvimento. Em Campina Grande (PB), na sede da Embrapa Algodão, foram realizados quatro minicursos tratando de transferência de tecnologias, dinâmica organizacional de cadeias produtivas, cultivo de tecidos vegetais e biotecnologia aplicada. No campus de Parnaíba da UFPI, foram oferecidos mais quatro minicursos tratando de economia criativa, análise de viabilidade econômica de projetos, georreferenciamento e estatística aplicada a economia rural. Finalmente, no encontro de Caruaru (PE), nas instalações do CAA-UFPE, foram oferecidos 11 minicursos, tratando de temas diversos, como valoração ambiental, derivativos agropecuários, avaliação de políticas públicas, aplicação de matriz de contabilidade social, industrialização no Brasil, arranjos produtivos locais, uso de séries temporais para análise de preços, além de outros bastante curiosos vinculados à música popular e design $\mathrm{x}$ inovação. Portanto, houve curso para diversos tipos de interesse. Esses cursos agregaram aos participantes novos conhecimentos.

\subsubsection{Publicações geradas}

Trata-se do esforço de organizar material acadêmico decorrente das apresentações realizadas pelos encontros na região. Em Campina Grande (PB), a

Tabela 2. Áreas temáticas dos trabalhos apresentados nos Encontros Regionais Nordeste da Sober: 2005-2015

\begin{tabular}{lcc}
\hline \multicolumn{1}{c}{ Áreas Temáticas dos trabalhos Apresentados } & Numero & Artigos \\
\cline { 2 - 3 } & & 25 \\
\hline I. Desenvolvimento Rural Sustentável e Desenvolvimento Rural & 315 & 18 \\
2. Agronegócio, Sistemas Produtivos, Cadeias Produtivas e Arranjos Produtivos & 220 & 168 \\
3. Comercialização e Mercados de Produtos Agrícolas & 158 & 13 \\
4. Políticas Públicas e Reforma Agrária & 89 & 7 \\
5. Agricultura Familiar e Ruralidade & 89 & 7 \\
6 Territórios, Ruralidade e Desenvolvimento & 88 & 6 \\
7. Agricultura, Tecnologia, Inovação e Difusão & 46 & 4 \\
8.Economia Solidária, Emprego, Empreendedorismo e Gestão no Campo & 25 & 22 \\
9. Comércio Exterior Agrícola & 22 & 2 \\
10. Questões Rurais e Educação no Campo & 1250 & 100 \\
Total & & \\
\hline
\end{tabular}

Fonte: Material dos Encontros (SEJAM, 2005; UFRB/EMBRAPA, 2007; UERN, 2008; UEPB/EMBRAPA, 2009; URCA, 2010; FACAPE, 2011; UESC, 2012; UFPI-REDE PRODEMA, 2013; UFPE-CAA,2014; UFAL-ARAPIRACA, 2015). 
equipe técnica local, formada por Cidoval Morais de Souza, Odilon Reny Ribeiro Ferreira da Silva, Maria Auxiliadora Lemos Barros e Robério F. dos Santos, resolveu fazer com alguns dos trabalhos apresentados um livro com o mesmo título do encontro, "Conhecimento Território e Sustentabilidade: Desafios para o Desenvolvimento do Nordeste". Esse livro está publicado pela Editora da Universidade Estadual da Paraíba (EDUEPB), Campina Grande-PB, 2010. Por esse mesmo caminho andou a equipe técnica do encontro da Sober em Parnaíba (PI). A Profa. Jaira Maria Alcobaça Gomes e o Prof. José Natanael Fontenele de Carvalho resolveram dedicar o exemplar Ano 16, n. 32, outubro 2014, da Revista Informe Econômico do curso de ciências econômicas da UFPI, para publicar alguns dos trabalhos apresentados. Esse número da revista teve como título Pluralidades Econômicas, Sociais e Ambientais: Interações para Reinventar o Nordeste Rural, o mesmo do congresso local. Nos outros encontros foram publicados os resumos expandidos e Anais, sob forma impressa ou eletrônica.

\subsubsection{A valorização da cultura regional}

Em muito dos encontros houve apresentação do folclore local, ou seja, lendas, cantos, danças, artesanato, brincadeiras, comidas típicas, que caracterizam a cultura popular local. Em Cruz das Almas (BA), o evento contou com a participação da Banda Juvenil Lyra Ceciliana, com repertório musical do mestre Luiz Gonzaga. Em Mossoró (RN), o hino nacional na abertura do evento foi executado pelo grupo de flautas do Conservatório de Música da UFRN, e houve uma apresentação do Quinteto de Saxofone do mesmo Conservatório. No Crato (CE), o evento contou com a Banda Cabaçal dos Irmãos Aniceto. No segundo encontro de Petrolina (PE), durante o momento cultural, o Forró Faísca, do tipo Pé de Serra, fez uma apresentação. Em Ilhéus (BA), o artista Romualdo Lisboa se apresentou com a peça "Coronel Teodorico", além da recepção dos congressistas por artistas do Bataclan, grupo de teatro local. Em Caruaru (PE), a recepção dos participantes foi realizada pela Companhia Pernas para Circulá - quadrilha de artistas sobre pernas de pau. Durante o evento, houve apresentações de Flávio Diniz com repertório MPB, a banda de Pífanos de João do Pife, as exposições fotográficas de Bento Gomes e Gustavo Penteado, a exposição de arte em madeira do artesão Venceslau e, no encerramento, apresentação da banda de forró Pé de Serra e da quadrilha Fora de Época, além de uma feirinha com barracas, oferecendo produtos da culinária típica do local. Em Arapiraca (AL) teve apresentação de Dona Flor e Jacó - violão e voz e saxofone, e do grupo de dança e música Coletivo Afrocaeté, além do grupo de capoeira Arte Brasil. A roda de capoeira foi tombada pela ONU em 2014 como patrimônio imaterial da humanidade. Essas manifestações culturais permitem ao visitante uma visão mais holística dessa região do País.

\subsubsection{Financiamento dos encontros}

As equipes locais responsáveis pelos encontros trataram de elaborar projetos para conseguir financiamento junto ao $\mathrm{CNPq}$, BNB, BB, agências estaduais de fomento à pesquisa, entre outros colaboradores. A regra geral tem sido conseguir menos do que o solicitado (ver Tabela 3).

Esses valores monetários cobriram algumas despesas que foram realizadas nos encontros, embora muitas outras despesas, para as quais não houve desembolso, não estejam incluídas, a exemplo das instalações para realizar os eventos, cedidas por prefeituras, universidades e pela Embrapa, sem que houvesse a necessidade de se pagar aluguel pelo uso desses espaços, além do trabalho voluntário de professores, alunos e também funcionários das instituições promotoras. Gráficas rodaram material a título de contribuição, agências de automóvel cederam veículos para transporte de pessoal, entre outras contribuições. Portanto, os custos dos encontros foram sempre maiores que os desembolsos monetários.

O valor monetário arrecadado e realizado por participante tem sido bastante modesto para esse tipo de evento, tendo variado a preços constantes de 2015, de $\mathrm{R} \$ 100,00$ a $\mathrm{R} \$ 300,00$ (per capita) para a maioria dos encontros. As exceções foram o primeiro em Petrolina, o mais caro, R\$ 799,00 per capita, devido à pouca participação de estudantes universitários da cidade, e o do Crato (CE), o mais barato, $\mathrm{R} \$ 81,00$ per capita, em decorrência da maciça participação de universitários da Urca, onde estava também sendo realizada a XI Semana de Economia promovida pela instituição.

As despesas iniciais do primeiro encontro foram orçadas em $R \$ 70.000,00$, mas chegaram a $R \$ 74.200,00$. O financiamento veio do Ministério de Desenvolvi- 
Tabela 3. Despesas com os encontros regionais Nordeste da Sober (valores correntes)

\begin{tabular}{|c|c|c|c|c|c|}
\hline \multirow{3}{*}{ Ano } & \multirow{3}{*}{ Local } & \multicolumn{4}{|c|}{ Despesas com o Encontro $(\mathrm{R} \$ 1,00)$} \\
\hline & & \multicolumn{2}{|c|}{ Valores Correntes } & \multicolumn{2}{|c|}{ Valores Constantes* } \\
\hline & & Previstas & Realizadas & Previstas & Realizadas \\
\hline 2005 & Petrolina - PE & 70.000 & 74.200 & 129.613 & 137.390 \\
\hline 2007 & Cruz das Almas - BA & 16.000 & 22.000 & 26.420 & 36.328 \\
\hline 2008 & Mossoró - RN & 30.000 & 25.000 & 45.628 & 38.023 \\
\hline 2009 & Campina Grande - PB & 61.625 & 23.802 & 94.618 & 36.545 \\
\hline 2010 & Crato $-\mathrm{CE}$ & 40.274 & 21.045 & 55.566 & 29.036 \\
\hline 2011 & Petrolina - PE & 38.148 & 36.312 & 50.297 & 47.877 \\
\hline 2012 & Ilhéus - BA & 72.757 & 72.757 & 88.740 & 88.740 \\
\hline 2013 & Parnaíba - PI & 63.000 & 26.700 & 72.786 & 30.847 \\
\hline 2014 & Caruaru - PE & 130.000 & 59.256 & 144.527 & 65.878 \\
\hline 2015 & Arapiraca - AL & 55.100 & 44.249 & 55.100 & 44.249 \\
\hline
\end{tabular}

* Deflator IGP-DI, Ipeadata (2015). Ano-base: $2015=100$.

Fonte: Projetos, relatórios dos encontros e entrevistas com os coordenadores.

mento Social e Combate à Fome (MDS), BNB, BB, Codevasf, Chesf, AD/Diper e Facepe. Teve ainda apoio da UFPE-Pimes, da Prefeitura Municipal de Petrolina, do Sebrae e da Embrapa Semiárido. Após o evento, o coordenador local teve dificuldade de fechar as contas devido a atraso na liberação de recursos de órgãos conveniados. Procurou, então, transferir alguns custos para a Sober, mas a diretoria teve dificuldade de assumir esses custos não programados. Além disso, dado que o primeiro encontro regional ocorreu no final de abril, foi visto como restritivo ao encontro nacional, que sempre é realizado no final de julho ou início de agosto, e isso poderia tirar participantes do encontro nacional, por preferirem apresentar seus trabalhos na própria região. O Conselho Regional Nordeste da Sober, informado sobre essa situação, procurou resolver as pendências relativas ao encontro regional. Passou a obter financiamento de entidades oficiais da região, principalmente do $\mathrm{BNB}$, com ampla participação e ajuda da diretoria da Sociedade. Houve também o cuidado de passar a fazer sempre o encontro regional após o nacional, e usar o nacional para estimular a participação de seus membros no regional, que passou a ocorrer em outubro ou novembro de cada ano.

O segundo encontro, em Cruz das Almas, contou com a participação do secretário da Sober, o que se tornou rotina nos demais encontros, ter alguém da direção nacional, às vezes mais de um representante, como presidente e secretário. $\mathrm{O}$ temor inicial da direção da
Sociedade relativo ao encontro regional ser restritivo ao funcionamento da entidade não foi verificado, tendo-se obtido resultado contrário ao esperado já a partir do segundo encontro, que demonstrou autonomia financeira e capacidade de ser complementar ao evento nacional. Em Campina Grande (2009), o então presidente da Sober, Joaquim Bento de Souza Ferreira Filho, que participou desse quarto encontro, deu para a imprensa local o seguinte depoimento:

“O encontro da região Nordeste é um dos orgulhos da Sociedade Brasileira de Economia Rural. É uma região que tem tido sucesso na realização do encontro regional e o modelo que está se desenvolvendo aqui no encontro de vocês está servindo de base para outras regiões do País que estão começando a pensar em realizar seu evento também. Para nós, é um caso de sucesso e motivo de muita satisfação" (UEPB/EMBRAPA, 2009).

Esse depoimento reflete uma nova compreensão política sobre o evento regional da Sociedade, também compartilhada na gestão do Prof. Sérgio Schneider (biênio 2011-2013), que chegou a ministrar uma palestra no evento de 2011, em Petrolina, e pelo seu sucessor e atual presidente (biênios 2013-2015 e 2015-2017), Marcelo José Braga, que tem participado com regularidade a esses encontros. Alguns dos resultados serão tratados no tópico adiante. 


\subsection{Prováveis efeitos na Sober decorrentes dos encontros regionais}

Neste item procura-se verificar se os encontros regionais da Sociedade pelo interior de estados do Nordeste tiveram algum efeito sobre o crescimento de associados do Nordeste na Sociedade e também se houve uma maior frequência nesses congressos anuais de participantes do Nordeste.

A Sociedade tem tido um crescimento modesto no número de sócios (Tabela 4). No período 2011-2016, passou de 393 para 445 sócios, com taxa de crescimento de $13 \%$. Analisando o primeiro efeito relativo ao crescimento de sócios na Sober da região Nordeste, os dados mostram que nessa região houve crescimento significativo de sócios na Sociedade, passando de 45 em 2011 para 129 em 2015, com retração para 96 em 2016, que pode, em parte, ser debitada à recessão econômica pela qual passa o País. Mesmo assim, manteve crescimento de $113 \%$ de filiados. Nesse mesmo período, 2011-2016, o crescimento e filiados à Sociedade no Norte passou de 45 para 96 (63\% a mais), no Centro-Oeste elevou- -se de 59 para 83 (39\% positivo) e, no Sul, de 103 alcançou 112 (8\% positivo). No Sudeste houve queda de 159 para 111 (30\% menos) no número de filiados. A situação de sócios por estado para o período, embora não tratada neste texto, encontra-se no Anexo 1.

O Congresso Nacional da Sober vem ocorrendo em geral nas capitais dos estados. Nos seis últimos anos (Tabela 5) foram realizados dois no Sudeste (o de 2011, em Belo Horizonte-MG, e o de 2012, em Vitória - ES), um no Norte (o de 2013 em Belém - PA), um no Centro-Oeste (o de 2014, em Goiânia - GO), e dois no Nordeste (o de 2015, em João Pessoa-PB, e o de 2016, em Maceió-AL), estes dois últimos, possivelmente, em decorrência dessa grande e efetiva mobilização. Em cada região onde ocorre o evento é sempre grande o número de participantes locais e ainda maior nos estados de ocorrência.

O número de participantes desses Congressos Nacionais tem variado bastante; contudo, sempre tem sido maior do que o número de sócios (Tabela 6), embora mantendo uma relação decrescente, à medida que aumenta o número de filiados.

Tabela 4. Sócios da Sober por região do Brasil: 2011-2016

\begin{tabular}{lcccccc}
\hline \multirow{2}{*}{ Região/país } & \multicolumn{7}{c}{ Anos } \\
\cline { 2 - 7 } & 2011 & 2012 & 2013 & 2014 & 2015 & 2016 \\
\hline Norte & 27 & 23 & 77 & 29 & 45 & 44 \\
Nordeste & 45 & 49 & 64 & 63 & 129 & 96 \\
Sudeste & 159 & 135 & 107 & 126 & 126 & 111 \\
Sul & 103 & 99 & 92 & 95 & 108 & 112 \\
Centro-Oeste & 59 & 71 & 69 & 108 & 87 & 82 \\
Brasil & 393 & 377 & 409 & 421 & 495 & 445 \\
\hline
\end{tabular}

Fonte: Secretaria da Sober (agosto 2016).

Tabela 5. Participantes do Congresso Nacional da Sober por região do País: 2011-2016

\begin{tabular}{|c|c|c|c|c|c|c|}
\hline Região/país & $\begin{array}{c}2011 \\
\text { Belo Horizonte- } \\
\text { MG } \\
24-27 / 07 \\
\end{array}$ & $\begin{array}{c}2012 \\
\text { Vitória-ES } \\
22-25 / 07\end{array}$ & $\begin{array}{c}2013 \\
\text { Belém-PA } \\
\text { 21-24/07 }\end{array}$ & $\begin{array}{c}2014 \\
\text { Goiânia-GO } \\
\text { 27-30/07 }\end{array}$ & $\begin{array}{c}2015 \\
\text { João Pessoa-PB } \\
\text { 26-29/07 }\end{array}$ & $\begin{array}{c}2016 \\
\text { Maceió-AL } \\
\text { 14-17/08 }\end{array}$ \\
\hline Norte & 44 & 44 & 118 & 57 & 83 & 61 \\
\hline Nordeste & 76 & 105 & 96 & 84 & 337 & 181 \\
\hline Sudeste & 410 & 442 & 210 & 233 & 209 & 167 \\
\hline Sul & 175 & 171 & 158 & 144 & 163 & 169 \\
\hline Centro-Oeste & 116 & 298 & 136 & 277 & 157 & 145 \\
\hline Estrangeiro & 1 & 1 & 2 & 2 & 4 & - \\
\hline Sem informação & 53 & 3 & 1 & 4 & 1 & - \\
\hline Brasil & 875 & 1064 & 721 & 801 & 954 & 673 \\
\hline
\end{tabular}

Fonte: Secretaria da Sober (agosto 2016). 
Tabela 6. Participantes dos congressos da Sober/número de sócios da Sober: 2011-2016

\begin{tabular}{lcccccc}
\hline \multicolumn{1}{c}{ Sober } & $\mathbf{2 0 1 1}$ & $\mathbf{2 0 1 2}$ & $\mathbf{2 0 1 3}$ & $\mathbf{2 0 1 4}$ & $\mathbf{2 0 1 5}$ & $\mathbf{2 0 1 6}$ \\
\hline Sócios (A) & 393 & 377 & 409 & 421 & 495 & 445 \\
Participantes dos Congressos (B) & 875 & 972 & 721 & 801 & 945 & 673 \\
(B/A) & 2,22 & 2,57 & 1,76 & 1,98 & 1,90 & 1,51 \\
(B-A/A) \% & 122 & 157 & 76 & 98 & 90 & 51 \\
\hline
\end{tabular}

Fonte: Secretaria da Sober (agosto 2016).

Tabela 7. Participantes do nordeste no Congresso Nacional da Sober

\begin{tabular}{lcccccc}
\hline \multicolumn{1}{c}{ Descrição } & $\mathbf{2 0 1 1}$ & $\mathbf{2 0 1 2}$ & $\mathbf{2 0 1 3}$ & $\mathbf{2 0 1 4}$ & $\mathbf{2 0 1 5}$ & $\mathbf{2 0 1 6}$ \\
\hline Participantes do Congresso da Sober (A) & 875 & 972 & 721 & 801 & 954 & 673 \\
Participantes do Nordeste no Congresso da Sober (B) & 77 & 107 & 96 & 84 & 337 & 181 \\
(B/A) \% & 8 & 11 & 13 & 10 & 35 & 27 \\
\hline
\end{tabular}

Fonte: Secretaria da Sober (agosto 2016).

Relativo ao segundo efeito de crescimento do número de participantes do Nordeste nos encontros da Sober para esses últimos anos, os números da Tabela 7 revelam crescimento dessa participação, chegando a $35 \%$ dos participantes em 2015, devido ao fato de a realização do congresso nacional ter sido em João Pessoa, e 27\% no congresso de 2016, em Maceió. Os nordestinos representam, em média, cerca de $10 \%$ dos participantes desses congressos. Dados mais completos desses participantes por estado e região estão no Anexo 2.

Outro possível efeito é o entusiasmo de pesquisadores do Nordeste com a Sober. O grupo do Ceará, com cerca de 40 sócios, o maior da região vinculado à Sociedade, pleiteou na assembleia do último congresso nacional da Sober, realizado em Maceió (AL), levar para Fortaleza (CE) o congresso nacional de 2018, tendo sido a única proposta apresentada para essa data. Em 2015 e 2016, o congresso nacional da Sociedade foi realizado na região e também será realizado o de 2018, o que demonstra certa mobilização do grupo regional dentro da instituição.

\section{Conclusão}

A decisão tomada pelo grupo regional de fazer os encontros regionais em cidades de porte médio no interior dos estados do Nordeste foi muito importante, devido à política de interiorização do ensino superior no País. Os cursos de pós-graduação formam jovens doutores que encontraram emprego nos campi de universidades no interior dos estados, incluindo também os do Nordeste. Com essa interiorização, a Sober chega a esse público. Outro fator importante observado pelo grupo com essa medida foi facilitar o acesso a estudantes da pós-graduação do Nordeste aos encontros regionais, já que a participação no encontro nacional é muito dispendiosa, implicando quase sempre grande deslocamento, hospedagem, alimentação além de taxa de inscrição bastante elevada, mesmo com os descontos habituais para estudantes da graduação e da pós-graduação. Contudo, um dos maiores impactos ocorre sobre os estudantes de graduação. Muitos trabalhos aprovados para publicação no evento regional não seriam selecionados para apresentação no evento nacional, bem mais competitivo em termos de quantidade e qualidade. $\mathrm{O}$ evento regional, que recebe uma quantidade menor de trabalhos, consegue selecionar contribuições de estudantes que estão iniciando a carreira acadêmica, oferendo a oportunidade, muitas vezes, de pela primeira vez do mesmo poder participar de um evento científico, de apresentar um trabalho ao público e de ter uma publicação em anais de congresso. Isto, por um lado, motiva bastante o graduando e ajuda a cativar um público que será congressista, quanto tiver mais maduro intelectualmente, do evento nacional. A ligação feita entre a Sober com este congressista se torna bastante forte.

Na esteira da interiorização do banco de desenvolvimento regional $\mathrm{BNB}$, do $\mathrm{BB}$, da universidade pública e privada e da rede de pesquisa agropecuária, capitaneada pela Embrapa e empresas estaduais de pesquisa na região, está também a interiorização da Sober. Tem destaque a participação financeira do BNB, que garan- 
tiu em quase todos os anos boa parte dos recursos necessários para realizar esses eventos como em termos de ampliação da "massa crítica" de conhecimentos gerados pela mobilização de pesquisadores.

Outro aspecto importante na região tem sido unir os pesquisadores e suas instituições para fazer o debate local, nacional e internacional, já que a economia da região é completamente nacionalizada e internacionalizada. A importância desses encontros tem sido criar convergências de interesses de pesquisadores e de instituições responsáveis pelo desenvolvimento regional, além de melhorar o acesso a estudantes de graduação e da pós-graduação a novos conhecimentos e servir de laboratório para iniciação de novos pesquisadores. Para a Sober, no âmbito nacional, serve como marketing institucional a custo baixo, e tem estimulado novos pesquisadores a se filiarem e participarem dos congressos da entidade. Nessa época de crise, quando a Sociedade passa cada ano a ter mais dificuldade de obter recursos de instituições governamentais para continuar funcionando, replicar esse modelo de regionalização no restante do país parece ser uma boa saída para a sua sobrevivência.

Essa já é uma realidade bem conhecida em outros países, como os Estados Unidos, mas ainda é novidade no Brasil. Quando a Sober iniciou, poucos eram os pesquisadores, não havendo espaço para regionalização. A realidade hoje é bem distinta, tanto quanto à dispersão dos grupos de pesquisa, como das restrições financeiras. A exitosa experiência dos encontros da Sober Nordeste aponta uma direção clara.

Embora os encontros da Sober no Nordeste tenham papel importante como fórum para discussão acadêmica, o desafio é aproximar o setor produtivo da região da Sociedade para ampliar a participação de empresas e outras organizações que façam pesquisas e utilizem resultados de pesquisas já realizadas.

\section{Referências}

BARROS, J. D'A. Teoria da História Vol. II - os primeiros paradigmas: positivismo e historicismo. 4 . ed. Petrópolis-RJ: Vozes, 2014.

CEJEM - Promoções e Treinamento/SOBER Regional Nordeste - 10 Forum Regional: economia agrícola. Centro de Convenções de Petrolina, 28 a 29 de abril de 2005. 56p.
CONSTANTINO, N. S. Pesquisa historica e análise de conteúdo: pertinencia e possibilidades. Disponível em: $<$ http://revistaseletronicas.pucrs.br $>$. Acesso em 18 jul. 2016.

FACAPE. Nordeste: desafios do desenvolvimento para a inclusão social. VI SOBER Nordeste Petrolina (PE) 19, 20 e 21 de outubro, 2011. 25p.

IPEADATA. Índice geral de preços: disponibilidade interna (IGP-DI). Disponível em: <www.ipeadata. com.br>. Acesso em: 12 set. 2016.

LESCURA, C. et al. A dinâmica entre a família e organização: um estudo de caso utilizando o método historiográfico e a técnica do genograma. XXXIII Encontro da ENANPAD 2009. São Paulo-SP, 19-23 set. 2009.

SAUERBRONN, F. F. e FARIA, A. A utilização do método histórico em pesquisa acadêmica de marketing in estratégia e negócios. Florianópolis, v. 2, n. 2, jul./dez. 2009.

SILVA, R. C. Método e sentido: a pesquisa e a historiografia na teoria de Jörn Rüsen. Fronteiras: Revista Catarinense de História, Florianópolis, n. 17, p. 33-55, 2009.

SOUSA, C. M. et al. (Orgs.). Conhecimento, território e sustentabilidade: desafios para o desenvolvimento rural no nordeste. Campina Grande: Eduepb, 2010. 328p.

UEPB/EMBRAPA. Conhecimento, território e sustentabilidade: desafios para o desenvolvimento rural do nordeste. IV Encontro Sober Regional Nordeste: de 3 a 5 de novembro de 2009. Campina Grande/Paraíba. Programação. CD.

UERN. Fruticultura e bioenergia: estratégias de desenvolvimento para o Nordeste. III Encontro SOBER REGIONAL NORDESTE 22 a 25 de outubro de 2008. Mossoró-RN. 144p.

UESC. Políticas públicas: agricultura e meio ambiente. VII SOBER NORDESTE: Ilheus 03 a 05 de outubro de 2012. CD.

UFAL. Desenvolvimento e crise: e o nordeste, como fica? X Congresso Regional da SOBER-NE Arapiraca-AL, 18 a 20 de novembro de 2015. CD.

UFPE-CAA. Novos desafios para o desenvolvimento: o nordeste tem sede de que? IX SOBER/NE - Programação Geral. Caruaru-PE, 29 a 31 de outubro de 2014.

UFPI. VIII SOBER NORDESTE- 06 a 08 de novembro de 2013 - Parnaíba-PI. Pluralidades Econômicas, Sociais e Ambientais: Informações para reinventar o Nordeste rural. Informe Econômico, ano 16, n. 32, set. 2014. (Publicação do Curso de Ciências Econômicas da UFPI) 
UFPI/Rede PRODEMA. Pluralidades econômicas, sociais e ambientais: Interações para reinventar o Nordeste rural. VIII SOBER/ NE- Parnaíba-PI, 6 a 8 de novembro de 2013. CD.

UFRB/EMBRAPA. Pobreza rural, interações e possibilidades de desenvolvimento sustentável. II SOBRE REGIONAL
NORDESTE. Cruz das Almas-BA, 21 a 23 de novembro de 2007. CD.

URCA. Mudanças climáticas globais e desenvolvimento rural do nordeste: inpactos econôicos, sociais e ambientais. V SOBER NORDESTE (XI Semana de Economia da URCA). Crato-CE, 24 a 26 de novembro de 2010. CD.

Todo o conteúdo deste periódico, exceto onde estiver identificado, está licenciado sob uma Licença Creative Commons (cc by 4.0 ) 
Tabela 1A. Sócios da Sober: 2011-2016

\begin{tabular}{|c|c|c|c|c|c|c|}
\hline Região & 2011 & 2012 & 2013 & 2014 & 2015 & 2016 \\
\hline Norte & 27 & 23 & 77 & 29 & 45 & 44 \\
\hline $\mathrm{AC}$ & 3 & 4 & 11 & 8 & 8 & 8 \\
\hline $\mathrm{AM}$ & 1 & 0 & 2 & 1 & 1 & 3 \\
\hline $\mathrm{AP}$ & 0 & 0 & 1 & 0 & 0 & 5 \\
\hline PA & 13 & 11 & 52 & 14 & 27 & 17 \\
\hline $\mathrm{RO}$ & 9 & 6 & 8 & 3 & 6 & 4 \\
\hline $\mathrm{RR}$ & 0 & 0 & 1 & 0 & 0 & 0 \\
\hline TO & 1 & 2 & 2 & 3 & 3 & 7 \\
\hline Nordeste & 45 & 49 & 64 & 63 & 129 & 96 \\
\hline AL & 1 & 0 & 1 & 0 & 2 & 9 \\
\hline BA & 5 & 8 & 13 & 6 & 14 & 7 \\
\hline CE & 16 & 17 & 21 & 24 & 40 & 27 \\
\hline MA & 0 & 2 & 4 & 0 & 0 & 3 \\
\hline PB & 1 & 5 & 7 & 5 & 20 & 20 \\
\hline PE & 11 & 12 & 10 & 16 & 33 & 17 \\
\hline PI & 3 & 0 & 0 & 1 & 1 & 1 \\
\hline $\mathrm{RN}$ & 7 & 5 & 7 & 9 & 17 & 10 \\
\hline SE & 1 & 0 & 1 & 2 & 2 & 2 \\
\hline Sudeste & 159 & 135 & 107 & 126 & 126 & 111 \\
\hline ES & 0 & 7 & 1 & 2 & 1 & 4 \\
\hline MG & 59 & 34 & 33 & 51 & 46 & 44 \\
\hline $\mathrm{RJ}$ & 12 & 17 & 14 & 14 & 15 & 10 \\
\hline $\mathrm{SP}$ & 88 & 77 & 59 & 59 & 64 & 53 \\
\hline Sul & 103 & 99 & 92 & 95 & 108 & 112 \\
\hline PR & 35 & 26 & 29 & 36 & 41 & 41 \\
\hline RS & 63 & 60 & 49 & 41 & 49 & 54 \\
\hline SC & 5 & 13 & 14 & 18 & 18 & 17 \\
\hline Centro-Oeste & 59 & 71 & 69 & 108 & 87 & 82 \\
\hline DF & 24 & 30 & 28 & 36 & 23 & 31 \\
\hline GO & 9 & 15 & 16 & 33 & 27 & 16 \\
\hline MS & 15 & 14 & 15 & 21 & 22 & 19 \\
\hline MT & 11 & 12 & 10 & 18 & 15 & 16 \\
\hline Brasil & 393 & 377 & 409 & 421 & 495 & 445 \\
\hline
\end{tabular}

Fonte: Secretaria da Sober (ago. 2016). 
Tabela 2A. Participantes dos Congressos da Sober: 2011-2016

\begin{tabular}{|c|c|c|c|c|c|c|}
\hline Região & 2011 & 2012 & 2013 & 2014 & 2015 & 2016 \\
\hline Norte & 44 & 44 & 118 & 57 & 83 & 61 \\
\hline $\mathrm{AC}$ & 6 & 8 & 14 & 12 & 12 & 7 \\
\hline $\mathrm{AM}$ & 2 & 4 & 3 & 2 & 1 & 1 \\
\hline $\mathrm{AP}$ & - & - & 2 & - & - & 3 \\
\hline PA & 18 & 20 & 85 & 30 & 60 & 35 \\
\hline $\mathrm{RO}$ & 16 & 9 & 9 & 5 & 7 & 9 \\
\hline $\mathrm{RR}$ & - & - & 1 & - & - & - \\
\hline TO & 2 & 3 & 4 & 8 & 3 & 6 \\
\hline Nordeste & 77 & 107 & 96 & 84 & 337 & 181 \\
\hline AL & 1 & - & 1 & - & 4 & 115 \\
\hline BA & 8 & 26 & 19 & 9 & 19 & 9 \\
\hline $\mathrm{CE}$ & 25 & 30 & 32 & 31 & 48 & 36 \\
\hline MA & 1 & 3 & 5 & - & - & 3 \\
\hline PB & 4 & 8 & 11 & 5 & 159 & 26 \\
\hline PE & 22 & 28 & 17 & 25 & 72 & 36 \\
\hline PI & 4 & 2 & 1 & 2 & 3 & 4 \\
\hline $\mathrm{RN}$ & 11 & 10 & 9 & 10 & 30 & 13 \\
\hline $\mathrm{SE}$ & 1 & - & 1 & 2 & 2 & 4 \\
\hline Sudeste & 410 & 442 & 210 & 233 & 209 & 117 \\
\hline MG & 221 & 113 & 71 & 99 & 80 & 64 \\
\hline $\mathrm{SP}$ & 158 & 157 & 103 & 108 & 105 & 95 \\
\hline RJ & 25 & 31 & 31 & 21 & 16 & 12 \\
\hline ES & 6 & 141 & 5 & 5 & 8 & 6 \\
\hline Sul & 175 & 171 & 158 & 144 & 163 & 169 \\
\hline RS & 101 & 93 & 87 & 67 & 76 & 83 \\
\hline SC & 15 & 20 & 25 & 21 & 24 & 26 \\
\hline PR & 59 & 58 & 46 & 56 & 63 & 60 \\
\hline Centro-Oeste & 116 & 205 & 136 & 277 & 157 & 145 \\
\hline DF & 48 & 111 & 49 & 62 & 59 & 48 \\
\hline GO & 20 & 37 & 30 & 139 & 35 & 28 \\
\hline MS & 28 & 30 & 27 & 38 & 36 & 39 \\
\hline MT & 20 & 27 & 30 & 38 & 27 & 30 \\
\hline Não Informado & 53 & 3 & 3 & 6 & 5 & - \\
\hline Total & 875 & 972 & 721 & 801 & 954 & 673 \\
\hline
\end{tabular}

Fonte: Sober/Itarget - Relatórios dos Congressos 2011-2016. 